ARTICLES

\title{
Instrumental Normativity: In Defense of the Transmission Principle*
}

\section{Benjamin Kiesewetter}

If you ought to perform a certain act, and some other action is a necessary means for you to perform that act, then you ought to perform that other action as well—or so it seems plausible to say. This transmission principle is of both practical and theoretical significance. The aim of this essay is to defend this principle against a number of recent objections, which (as I show) are all based on core assumptions of the view called actualism. I reject actualism, provide an alternative explanation of its plausible features, and present an independent argument for the transmission principle.

Suppose you ought to go to the Radiohead concert, and in order to do so, you need to buy a ticket. Then it seems plausible to say that you ought to buy a ticket for the Radiohead concert. More generally speaking, if you ought to perform a certain act, and some other action is a necessary means for you to perform that act, then it seems plausible to say that

\footnotetext{
* Parts of the material contained in this essay have been presented at the HumboldtPrinceton Graduate Conference in Philosophy at Humboldt University, Berlin, in August 2012; the Konstanz Philosophical Retreat on Insel Reichenau in September 2013; the Practical Philosophy/Ethics colloquium at Humboldt University, Berlin, in January 2014; and the Australian National University, Canberra, in April 2014. I would like to thank the participants for their feedback and especially Mark Harris for his comments at the conference in Berlin. I am also grateful to Hannah Altehenger, Vuko Andric, John Broome, Christoph Fehige, Julian Fink, Simon Gaus, Jan Gertken, Frank Jackson, Felix Koch, Niko Kolodny, Leon Leontyev, Leo Menges, Andreas Müller, Thomas Schmidt, Nicholas Southwood, Jonathan Way, and Jack Woods, as well as Donald Hubin and Henry S. Richardson from the editorial board, two referees, and seven associate editors for written comments and/or helpful discussion of earlier versions of this essay. This work was supported by the ARC Discovery Grant DP120101507 and the Deutsche Forschungsgemeinschaft (SFB 644).
} 
you ought to perform that other action, too. 'Ought', that is, transmits to necessary means - or so it seems plausible to say. I shall refer to this as the transmission principle:

The transmission principle: If A ought to $\varphi$, and $\psi$-ing is a necessary means for A to $\varphi$, then A ought to $\psi{ }^{1}$

The transmission principle is of both practical and theoretical significance. For one, it validates a certain form of practical inference which seems both plausible and widely used. For another, it figures as a premise in a number of philosophical arguments concerning other important questions. For example, Mark Schroeder's account of means/endincoherence presupposes the transmission principle, Kieran Setiya has argued on its basis against the wide-scope account of instrumental rationality, and Jonathan Way relies on the transmission principle in his argument for skepticism about so-called wrong kinds of reasons. ${ }^{2}$

Despite its great intuitive appeal, the transmission principle has recently come under attack. ${ }^{3}$ My aim in this essay is to defend it against an important challenge, which, as I argue, underlies a number of more specific objections that have been brought forward against the transmission principle in the recent literature, and finally to provide an independent argument for it. After some preliminary remarks in Section I, I present

1. See, e.g., Kieran Setiya, “Cognitivism about Instrumental Reason,” Ethics 117 (2007): 649-73, 660: "If you should do $E$, all things considered, and doing $M$ is a necessary means to doing $E$, you should do $M$, all things considered, too." Similar principles about the transmission from 'oughts' and reasons to perform an action to 'oughts' and reasons to take the necessary means to that action have been embraced (among others) by Michael Bratman, "Intention, Practical Rationality, and Self-Governance," Ethics 119 (2009): 411-43, 424; Stephen L. Darwall, Impartial Reason (1983; repr., Ithaca, NY: Cornell University Press, 1985), 16; T. M. Scanlon, Being Realistic about Reasons (Oxford: Oxford University Press, 2014), 85; Mark Schroeder, "Means-End Coherence, Stringency, and Subjective Reasons," Philosophical Studies 143 (2009): 223-48, 234 and 245; Sharon Street, "Constructivism about Reasons," Oxford Studies in Metaethics 3 (2008): 207-45, 228; and Jonathan Way, "Defending the WideScope Approach to Instrumental Reason," Philosophical Studies 147 (2010): 213-33, 225.

2. See Schroeder, "Means-End Coherence"; Setiya, "Cognitivism about Instrumental Reason"; and Jonathan Way, "Transmission and the Wrong Kind of Reason," Ethics 122 (2012): 489-515. For further discussion of Setiya's objection, see also Bratman, "Intention, Practical Rationality, and Self-Governance"; John Brunero, "Self-Governance, Means-Ends Coherence, and Unalterable Ends,” Ethics 120 (2010): 579-91. Way's argument is officially based on a more liberal transmission principle which is not restricted to necessary means, but he mentions himself that his principle is open to objections that do not apply to a transmission principle restricted to necessary means, and that his argument could also be framed in terms of such a more restricted principle (see Way, "Transmission," 496 n. 14).

3. See John Broome, Rationality through Reasoning (Chichester: Wiley-Blackwell, 2013), 126; Ulrike Heuer, "Reasons and Impossibility," Philosophical Studies 147 (2010): 235-46; Niko Kolodny, "Instrumental Reasons," in The Oxford Handbook of Reasons and Normativity, ed. Daniel Star (forthcoming), secs. 2-3; Joseph Raz, "The Myth of Instrumental Rationality," Journal of Ethics and Social Philosophy 1 (2005): 2-28, sec. 1. 
and discuss this challenge in Section II. I call it "the actualist challenge," because it is based on Frank Jackson and Robert Pargetter's case for the view they call "actualism." I show that actualism is incompatible not only with the transmission principle but also with the more fundamental principle that practical 'oughts' must be jointly satisfiable. I reject actualism on this ground and provide an alternative explanation of its plausible features, which is compatible with both the principle of joint satisfiability and the transmission principle. This discussion provides the background for Section III, in which I address three recent objections to the transmission principle, put forward by John Broome, Joseph Raz, and Niko Kolodny. I demonstrate how these objections rely on the same actualist intuitions that also threaten the requirement of joint satisfiability, and again provide an interpretation of the alleged counterexamples that is compatible with the transmission principle. In Section IV, I conclude my defense of the transmission principle by presenting an independent argument for it. Drawing on the foregoing discussion, I argue that the transmission principle is entailed by the best explanation of the joint satisfiability of 'oughts'.

\section{PRELIMINARIES}

Let me begin with some clarificatory remarks about the content of the transmission principle. Its two main conceptual ingredients are the notions of 'ought' and of 'necessary means'. In this essay, I will understand the transmission principle such that 'ought' is taken to be the concept that settles the conclusions of practical deliberation - the kind of deliberation that aims to answer the question of what, all things considered, one has most reason to do. ${ }^{4}$ The reasons in question can be practical reasons of all sorts, encompassing hedonic, prudential, and moral reasons. Following John Broome and others, we can identify this practical or deliberative sense of 'ought' as the sense in which believing that one ought to $\varphi$ rationally commits one to intending to $\varphi$. In other words, the 'ought' in question is the one appealed to in the common understanding that it is irrational, or akratic, to refrain from intending what one believes one ought to do. ${ }^{5}$

4. This is not to deny that there are instances of practical reasoning that conclude in intentions, as John Broome argues in "Practical Reasoning," in Reason and Nature: Essays in the Theory of Rationality, ed. José Luis Bermúdez and Alan Millar (Oxford: Clarendon, 2002), $85-111$.

5. See Broome, Rationality through Reasoning, 22-25, who takes this sense of 'ought' to be central. Other authors who have emphasized the connection between 'ought'- or 'most reason'-judgments and rational intentions include Niko Kolodny, "Why Be Rational?," Mind 114 (2005): 509-63, 521; T. M. Scanlon, What We Owe to Each Other (Cambridge, MA: Belknap, 1998), 25; and Michael Smith, The Moral Problem (Oxford: Blackwell, 1994), 148. Nomy Arpaly, 
As regards the second central notion of the transmission principle, I shall employ a notion of 'means' according to which a means is a type of action $\psi$ that helps to bring about some state of affairs, where the state of affairs relevant for the transmission principle is the one in which the agent performs some other action $\varphi$. As Niko Kolodny emphasizes, "helping to bring about" need not be causing, but may also be constituting, or preventing something that would prevent A's $\varphi$-ing. ${ }^{6}$ I use the term "action" such that it includes both positive and negative actions (i.e., omissions), and I take it that refraining from doing something can be a means, for example in virtue of preventing a preventer. ${ }^{7}$

Next, I would like to emphasize the difference between the transmission principle and two other principles that resemble it in some respect. First, the transmission principle should not be conflated with the principle of instrumental rationality, according to which we ought, or are rationally required, to intend what we believe to be the necessary means to ends we intend. ${ }^{8}$ The principle of instrumental rationality is concerned with the relation between our attitudes; it demands coherence between our intentions and means/end-beliefs. The transmission principle, in contrast, is not concerned with our attitudes at all, but with the relation between what we ought to do and what are in fact necessary means to doing it. This essay is concerned with instrumental normativity, not with instrumental rationality. It is therefore not affected by recent arguments that call into question the existence of a valid principle of instrumental rationality on the ground that any such principle would license implausible "bootstrapping" of reasons, that is, the creation of reasons by merely intending an action. ${ }^{9}$

Second, the transmission principle should also not be conflated with the deontic closure principle, according to which we ought to do something whenever our doing it logically follows from our doing something

\footnotetext{
"On Acting Rationally against One's Best Judgment," Ethics 110 (2000): 488-513, is often understood as denying this connection, but as she notes herself, she actually endorses the view that a mismatch between normative all-things-considered judgments and intentions shows agents to be "less than fully rational" (491). I take the term "deliberative 'ought" from Bernard Williams, "Ethical Consistency," Proceedings of the Aristotelian Society, Supplementary Volumes 39 (1965): 103-38, 124.

6. See Kolodny, "Instrumental Reasons," sec. 1.

7. Ibid. Specifying the kind of necessity involved in talk of necessary means is a difficult task that is beyond the scope of this essay. I shall rely on an intuitive sense of what it means to say that something is necessary or possible for an agent. The arguments to come are compatible with different conceptions of the necessity involved.

8. For a recent discussion of this principle, see Niko Kolodny and John Brunero, "Instrumental Rationality," in The Stanford Encyclopedia of Philosophy, ed. Edward N. Zalta (Fall 2013 ed.), http:/ / plato.stanford.edu/archives/fall2013/entries/rationality-instrumental/.

9. As brought forward, e.g., by Raz, "The Myth of Instrumental Rationality."
} 
else we ought to do. ${ }^{10}$ This latter principle famously invites Ross's paradox: it licenses the inference from "you ought to mail the letter" to "you ought to mail the letter or burn it,"11 and thus (even worse) to "if you burn the letter, then you do something that you ought to do." Regardless of whether one takes Ross's paradox to provide a sufficient reason for rejecting the deontic closure principle, it is important to note that the transmission principle is not susceptible to an objection of this kind. The transmission principle states only that 'ought' transmits to necessary means and thus does not entail that it transmits to necessary side effects or logical implications.

\section{THE ACTUALIST CHALLENGE}

In this section and the next, I shall be concerned with what I take to be the most important challenge to the transmission principle - a challenge that I shall suggest is also at play in a number of recent objections to it. Although the details of these objections vary significantly, I shall argue that they are all based on the same idea. The worry is that it seems implausible to say that one ought to take the necessary means to an action one ought to perform if one will not actually perform this action or is at least very likely not to perform it. To put it succinctly: even if you ought to attend the Radiohead concert, what is the point of buying a ticket if you will not go there anyway? I call this "the actualist challenge" because it rests on intuitions that also seem to support the view that Frank Jackson and Robert Pargetter introduced as "actualism." 12

Before discussing the explicit objections to the transmission principle in the next section, I will first address what I take to be their common systematic core. As the more detailed discussion of counterexamples in the next section will reveal, the arguments against the transmission principle are all based on actualist assumptions, and I will therefore begin by discussing actualism in its own right. I start by introducing the distinction between actualism and possibilism and by demonstrating that actualism is incompatible with the transmission principle (II.A). Subsequently, I defend the transmission principle by presenting an independent argument against actualism (II.B) and an alternative explanation of

10. See, e.g., Paul McNamara "Deontic Logic," in The Stanford Encyclopedia of Philosophy, http:/ / plato.stanford.edu/archives/fall2010/entries/logic-deontic/, sec. 2.1; Walter SinnottArmstrong, "Moral Dilemmas and 'Ought and Ought Not," Canadian Journal of Philosophy 17 (1987): 127-39, 136.

11. See Alf Ross, "Imperatives and Logic," Theoria 7 (1941): 53-71, 61-62.

12. See Frank Jackson and Robert Pargetter, "Oughts, Options, and Actualism," Philosophical Review 95 (1986): 233-55. 
actualism's plausible features (II.C). All of this provides the background for my responses to the objections addressed in Section III.

\section{A. Actualism, Possibilism, and the Transmission Principle}

To begin with, consider the following famous example from Frank Jackson and Robert Pargetter:

Professor Procrastinate receives an invitation to review a book. He is the best person to do the review, has the time, and so on. The best thing that can happen is that he says yes, and then writes the review when the book arrives. However, suppose it is further the case that were Procrastinate to say yes, he would not in fact get around to writing the review. Not because of incapacity or outside interference, but because he would keep on putting the task off. (This has been known to happen.) Thus, although the best that can happen is for Procrastinate to say yes and then write, and he can do exactly this, what would in fact happen were he to say yes is that he would not write the review. Moreover, we may suppose, this latter is the worst that can happen. It would lead to the book not being reviewed at all. ${ }^{13}$

Jackson and Pargetter introduce this case in order to illustrate the contrast between two views about how the goodness of outcomes is related to what an agent ought to do. The view that they advance is as follows:

Actualism: A ought to $\varphi$ if, and only if, $\varphi$-ing is an option such that what would happen if $\mathrm{A} \varphi$-s is (expectably) ${ }^{14}$ better than what would happen if A does not $\varphi$.

Actualism implies that Procrastinate ought to reject the invitation, for what would happen if he declines is better than what would happen if he accepts. Possibilism, in contrast, denies this. This view is spelled out in different ways in the literature, but the basic idea of possibilism is that

13. Ibid., 235. The example is a variant of a case first introduced and discussed by Holly S. Goldman, "Doing the Best One Can," in Values and Morals, ed. Alvin I. Goldman and Jaegwon Kim (Dordrecht: Reidel, 1978), 185-214, 185-86.

14. Depending on whether actualism is understood as including this proviso or not, and provided that the relevant probabilities are the evidential probabilities of the agent, the resulting view is an objectivist or perspectivist version of actualism. See Benjamin Kiesewetter, "Ought' and the Perspective of the Agent," Journal of Ethics and Social Philosophy 5 (2011): 1-24, for further discussion and literature on the debate between objectivists and perspectivists. For objectivist versions of actualism, see, e.g., Holly S. Goldman, "Dated Rightness and Moral Imperfection,” Philosophical Review 85 (1976): 449-87; and Jackson and Pargetter, "Oughts, Options, and Actualism." For perspectivist versions, see, e.g., Lou 
whether A ought to $\varphi$ does not depend on what would (likely) happen if A $\varphi$-ed, but on what could (likely) happen as a result of A's exercising his agency. ${ }^{15}$ Thus, if the consequences of an action would be bad only because the agent would do a lot of other stupid things which she ought not to do and could avoid doing, the possibilist claims that this is irrelevant to whether the agent ought to perform the action. Possibilists therefore hold that Procrastinate ought to accept the invitation, because even though he would not actually write the review, what counts is that he could do it and would have most reason to do so.

The distinction most naturally arises in the context of consequentialist theories, but every view that takes consequences (or expectable consequences) of actions to be normatively relevant faces an analogous question. For simplicity's sake, I shall stipulate in the following discussion that no other relevant factors are present. How, then, do the case of Procrastinate and the distinction between possibilism and actualism bear on the transmission principle? Well, let us suppose that Procrastinate's accepting the invitation to write the review is a necessary means to writing it (he will receive the book prior to publication only if he accepts, and this is necessary for writing the review in time). If he were to refuse, things would be better than if he were to accept; therefore, actualism implies that Procrastinate ought to refuse. However, if he were to write the review, things would also be better than if he were not to write the review; actualism therefore also implies that he ought to write the review. Hence, according to actualism, Procrastinate ought to write, but he also ought not to accept, even though accepting is a necessary means to writing. So if actualism is true, then the transmission principle is false. ${ }^{16}$

Goble, "Utilitarian Deontic Logic," Philosophical Studies 82 (1996): 317-57; Frank Jackson, "Procrastinate Revisited," Pacific Philosophical Quarterly 95 (2014): 634-47. Except when I explicitly say otherwise, I mean to be neutral between objectivist and perspectivist versions of actualism and possibilism in the following discussion.

15. See, e.g., Goldman, "Doing the Best One Can," for an objectivist version, and Michael Zimmerman, Living with Uncertainty (Cambridge: Cambridge University Press, 2008), chap. 3, for a perspectivist version of possibilism. Even within the objectivist and the perspectivist camp, there are different conceptions of possibilism, and they all have been argued to face problems. For a recent discussion, see Jacob Ross, "Actualism, Possibilism, and Beyond," Oxford Studies in Normative Ethics 2 (2012): 74-96. My concern here lies with the question of whether actualism is true, since actualism is incompatible with the transmission principle. The question of what is the best alternative to actualism is beyond the scope of this essay.

16. This does not hold true for Goldman's version of actualism (in her "Dated Rightness"), which takes prescriptions of present acts as basic and then makes prescriptions of future acts dependent on whether they are compatible with prescriptions of present acts. The arguments in this essay are addressed only at versions of actualism that pose a threat to 


\section{Ethics July 2015}

It might be objected that the Procrastinate case is described in an incoherent way. Jackson and Pargetter assume both that Procrastinate will not write the review and that he can do it. One might worry that the former assumption presupposes some form of determinism that falsifies the latter. And if we no longer can assume that Procrastinate can write the review, then it follows that writing is not an option for him, and as a result, the actualist's verdict on the Procrastinate case no longer threatens the transmission principle.

This worry seems to me unjustified. For one, the assumption that Procrastinate will not write the review does not presuppose determinism, at least as long as we allow that future contingents have truth values, which is a respectable (though admittedly not uncontroversial) position. For another, even if assuming that Procrastinate will not write did presuppose determinism, this would not seem to undermine the assumption that Procrastinate can write the review in the relevant sense of 'can', which refers to an ability of his. Moreover, the basic structure of the case remains the same if we substitute the assumption that Procrastinate will not write the review with the assumption that he is very unlikely to write it (which in turn is incontrovertibly compatible with the assumption that he can write it). The version of actualism that focuses on expectable rather than actual value (mentioned in the definition of actualism above) would still yield the result that Procrastinate ought to write, but ought not to accept. For simplicity's sake, I shall go on to use the nonprobabilistic version of the example, but everything I am going to say could just as well be expressed in probabilistic terms.

A further worry has to do with a potential ambiguity in the assumption that Procrastinate can write the review, which results from the fact that the 'can' refers to the time at which Procrastinate has to decide whether to accept the invitation (time $t$, for short), not the time at which Procrastinate would write the review $\left(t^{\prime}\right)$. It might be claimed that Procrastinate can, at $t$, write the review at $t^{\prime}$, only in the weak sense in which Procrastinate is at $t$ able to do something at $t$, which results in his being able at $t^{\prime}$ to write the review. Next, it might be argued that in order for it to be true, at $t$, that Procrastinate ought to write the review, a stronger condition has to be satisfied, according to which Procrastinate is at $t$ able

the transmission principle, such as Jackson and Pargetter's. Note, however, that Goldman's actualism has other major problems. According to it, since Procrastinate will not write the review, he ought to not-accept the invitation, and since he ought to not-accept the invitation, it is not the case that he ought to write the review. Goldman's actualism thus permits agents to refrain from actions that they can perform, and which are clearly best, for the mere reason that they will not perform them-an implication that eventually led Goldman herself to reject her view in favor of a possibilist account (see her "Doing the Best One Can," 198-200). 
to do something that guarantees his writing the review at $t^{\prime} .{ }^{17}$ It would follow from these assumptions that actualism does not in fact prescribe writing the review, since this is not, in the relevant sense, an option for Procrastinate.

Again, this seems to me misguided. First, we very rarely have the kind of control over our future actions that is required by the strong condition. Accepting this condition will thus rule out a multitude of intuitively plausible judgments about what we ought to do in the future. The weaker condition, which merely requires present control over present actions leading to future control over future actions, captures our reflected judgments in a better way and is therefore preferable (at least in the absence of strong independent reasons for accepting the strong condition). Second, even if it may seem most natural to interpret Jackson and Pargetter's example otherwise, it is actually compatible with the assumption that Procrastinate has the kind of control required by the strong condition. That he will not write the review even if he accepts the invitation to write it does not entail that he cannot at the time of accepting it do something that guarantees his writing the review. ${ }^{18}$ Thus, even if the strong condition is accepted, the result that actualism prescribes [rejecting the invitation] as well as [writing the review] can be preserved by adding further assumptions to the example that satisfy the condition.

\section{B. Against Actualism}

In order to defend the transmission principle against actualism, I shall first provide an independent argument against actualism and then explain the intuitions that support actualism's verdict on the Procrastinate case on an alternative basis. Let me begin with the first of these tasks by recalling a familiar point from the literature on this topic: actualism is incompatible not only with the transmission principle but with a variety

17. While employing the weak condition in previous work (Goldman, "Dated Rightness," 453), Goldman, "Doing the Best One Can," 195, seems to embrace a variant of the strong condition. Her argument is that a prescription that does not satisfy the strong condition "would be pointless, because the agent could not make practical use of the prescription; he could not successfully choose to carry it out" (ibid., 194). The issue is complicated by the particular conditional analysis that Goldman suggests, but understood as a general argument for the strong condition, this does not seem to be convincing. If an agent chooses, at $t$, to $\left[\varphi\right.$ at $t$ and $\psi$ at $\left.t^{\prime}\right]$, and then chooses at $t$ to $\varphi$, and chooses at $t^{\prime}$ to $\psi$, then he could count as having successfully chosen to carry out a prescription to $[\varphi$ at $t$ and $\psi$ at $\left.t^{\prime}\right]$, independently of whether the strong condition is true. We often make such longterm decisions and carry them out successfully, even if we do not have present control over our future actions.

18. See also Goldman, "Doing the Best One Can," 199-200. 
of other principles that seem intuitively compelling. ${ }^{19}$ The most prominent one is the so-called distribution principle:

Distribution: If A ought to $[\varphi$ and $\psi]$, then A ought to $\varphi$ and A ought to $\psi$.

As we have seen, actualism implies that Procrastinate ought not to accept, for what would happen were he not to accept is better than what would happen if he were to accept. However, actualism also implies that Procrastinate ought to [accept and write], for what would happen if he were to [accept and write] is also better than what would happen if he were not to [accept and write]. It follows that actualism is incompatible with distribution. Actualism also violates:

Agglomeration: If A ought to $\varphi$ and A ought to $\psi$, then A ought to $[\varphi$ and $\psi]$.

Given that, as actualism implies, Procrastinate ought to [accept and write] and Procrastinate ought to [not-accept], agglomeration entails that Procrastinate ought to [accept and write and not-accept]. Since this is not an option for him, actualists need to deny agglomeration.

Despite their apparent plausibility, both distribution and agglomeration have been contested, and actualists are usually happy to reject them. ${ }^{20}$ Although I do not find the reasons that have been brought forward against these principles convincing, I also do not know of an independent argument in favor of them which does not beg the question against the actualist. A better way to argue against actualism starts from the observation that it violates:

Joint satisfiability: If A ought to $\varphi$ and A ought to $\psi$, then it is possible for A to $[\varphi$ and $\psi]$.

This is again because actualism entails both that Procrastinate ought to [accept and write] and that Procrastinate ought to [not-accept]. I shall argue that the truth of joint satisfiability is essential for the role that 'ought'-judgments play in practical deliberation, and that the fact that actualism is incompatible with joint satisfiability is therefore a conclusive reason to reject actualism about the deliberative 'ought'.

19. See, e.g., Zimmerman, Living with Uncertainty, 121.

20. Jackson and Pargetter, "Oughts, Options, and Actualism," 247-48, argue against distribution by counterexample. However, the example has essentially the same structure as the Procrastinate case; it can be treated in the same way (compatibly with distribution) as I shall suggest treating the Procrastinate case in the next section. 
First, recall that in practical deliberation we are concerned with the sense of 'ought' in which believing one ought to $\varphi$ rationally commits one to intending to $\varphi$. Now, if joint satisfiability were false, agents could truly believe that they ought to perform actions that they truly believe to be incompatible. Consequently, they could be rationally committed to intending actions that they truly believe to be incompatible-simply by believing the truth about what they ought to do. Moreover, since it is irrational to intend each of two actions that one believes to be incompatible with each other, it follows that agents in such situations would be necessarily irrational just because they believe the truth about what they ought to do. Either they do not intend what they believe they ought to do, which is irrational, or they form these intentions and thereby end up intending actions they believe to be incompatible with each other, which is also irrational. ${ }^{21}$ These implications strike me as unacceptable.

Second, recall that the deliberative 'ought' is supposed to settle the conclusion of practical deliberation about what to do. Joint satisfiability tells us that if you ought to, all things considered, do one thing, and you ought to, all things considered, do some other thing, then it must be possible for you to do both of these things. As I see it, the deliberative 'ought' is that conception of 'ought' of which we may say with certainty that it renders this claim true. If the 'oughts' in question were to require practically incompatible actions, then they could not settle the conclusion of practical deliberation, for we would still need an answer to the practical question of what to do. For example, if Procrastinate concludes that he ought to [not-accept], and that he ought to [accept and write], then he has not settled the practical question of what to do. It might be argued that circumstances can be such that there is no answer to the practical question of what to do. This seems to me correct. But my argument does not presume that there is always an answer to this question. The point is merely that an 'ought'-statement that allows for the violation of joint satisfiability could not count as an answer to that question, and thus could not be a true statement about the deliberative 'ought'.

Some authors, such as Bernard Williams, reject joint satisfiability for moral obligations in order to make room for the possibility of tragic ${ }^{22}$

21. An editor has suggested that it might not be irrational to intend each of a number of actions while believing that one of them (which one cannot yet identify) is incompatible with the others. I do not deny this. The argument merely assumes that it is irrational to intend each of two actions that one believes to be directly incompatible with each other. Similarly, I do not deny that one could rationally believe that one ought to perform each of a number of actions, while believing that one of these actions (which one cannot yet identify) is incompatible with the others. What joint satisfiability rules out (correctly, I believe) is merely that all of these beliefs could be true.

22. By a tragic moral dilemma I mean a dilemma that involves moral obligations to perform incompatible actions. Such dilemmas are sometimes called "genuine" moral di- 
moral dilemmas. ${ }^{23}$ This does not affect the present argument. Even if joint satisfiability is invalid for moral obligations, it does not follow that it is likewise invalid for the all-things-considered 'ought' of practical deliberation. If moral obligations conflict, then the right conclusion to draw is rather that moral obligations do not necessarily amount to allthings-considered 'oughts'. This is also the conclusion that proponents of conflicting obligations in fact draw; Williams, for example, explicitly embraces joint satisfiability for the deliberative 'ought'. ${ }^{24}$

Jackson and Pargetter, however, have a different reply to the charge that actualism violates joint satisfiability. First, they claim that 'oughts' are implicitly relativized to sets of options. Second, they argue that 'oughts' need to be jointly satisfiable only insofar as they are relativized to the same set of options: it is possible, for example, that out of the options of having one glass of liquor and having two, you ought to have one; while out of the options of having one glass of liquor and having none, you ought to have none. Third, they hold that the question of whether A ought to $\varphi$ needs to be understood as relative to the set of $\varphi$-ing and the option that A would take if A were not to $\varphi$. Against the background of these assumptions, Jackson and Pargetter argue that the problem of incompatible prescriptions is only apparent: that Procrastinate ought to [accept-and-write] and ought to [not-accept] poses no difficulties, for the former 'ought' is relative to the set of options [accepting-andwriting; and not-(accepting-and-writing)], while the latter is relative to the different set of options [accepting; and not-accepting]. ${ }^{25}$

This reply is, I think, entirely ineffective against the arguments that I have given. There are two options to consider. Let us first assume that Jackson and Pargetter are concerned with the same, deliberative sense of 'ought' that is the topic of this essay and do indeed think that different deliberative conclusions about what one ought to do are to be understood relative to different sets of options. Either this view is compatible with my claim that true deliberative conclusions about what one ought to do satisfy joint satisfiability, or not. If it is compatible with this claim, then nothing in Jackson and Pargetter's reply undermines the

lemmas. But I do not think that genuine dilemmas need to be tragic. Conflicts of equally strong or incommensurable moral reasons can provide genuine moral dilemmas that are not tragic. So in my view, one need not allow for tragic moral dilemmas (thus denying the joint satisfiability of moral obligations) in order to allow for genuine moral dilemmas.

23. See Williams, "Ethical Consistency," 117-23. Since joint satisfiability is entailed by the conjunction of agglomeration and 'ought' implies 'can', Williams also denies agglomeration for moral obligations.

24. Ibid., 123-24; Bernard Williams, "Ought and Moral Obligation," reprinted in Moral Luck (Cambridge: Cambridge University Press, 1981), 114-23, 119. See also John F. Horty, "Reasoning with Moral Conflicts," Noûs 37 (2003): 557-605, 588-89.

25. See Jackson and Pargetter, "Oughts, Options, and Actualism," secs. 5-6. 
arguments that I have given for it. If it is not compatible with my claim, then the arguments I have given are likewise arguments against the view that the deliberative 'ought' is to be understood in the option-relative manner they suggest: if the option-relative account entails that incompatible practical conclusions about what to do can be true, then so much worse for this account!

Indeed, it seems independently implausible that all-things-considered conclusions of practical deliberation are to be understood as relative to subsets of options rather than the set of all options (if relative to options at all). Of course, in practice we cannot but reduce the options that we explicitly consider to some relevant subset. ${ }^{26}$ But it does not follow from this that the content of the deliberative question "What ought I to do?", and the content of deliberative conclusions, is itself relativized to subsets of options. On the contrary, it is difficult to see how such relativized judgments could play the role they are supposed to play, namely as a rational basis for making a decision. Making a decision is to exclude, in practice, all alternative options, and it does not seem rational to do so on the basis of a judgment that an action is recommended out of a subset of options. And so it seems to me more charitable, after all, to think that Jackson and Pargetter must have some other sense of 'ought' in mind, which does not serve as a rational basis for decision making. In this case, again, nothing in their reply casts doubt on the arguments to the effect that the deliberative 'ought' must obey joint satisfiability.

In light of this, one might attempt to rescue actualism by maintaining that the deliberative question is concerned only with what to do now, and that actualism's verdicts about what Procrastinate ought to do now do not violate joint satisfiability. ${ }^{27}$ This reply seems misguided in several respects. First of all, as examples in the literature illustrate, actualism violates joint satisfiability also in purely synchronic cases that are only concerned with the question of what to do now. ${ }^{28}$ Second, it strikes

26. As Kolodny, "Instrumental Reasons," sec. 3, n. 31, points out.

27. This reply was put forward by an editor. It is also suggested by remarks in Jackson, "Procrastinate Revisited," sec. 6, and Kolodny, "Instrumental Reasons," sec. 3, n. 31.

28. See Goldman, "Doing the Best One Can," 186; Jackson and Pargetter, "Oughts, Options, and Actualism," 236. Interestingly, in a revision of his earlier view, Jackson now rejects actualism for synchronic cases because he wants to "avoid inconsistent answers concerning what agents ought to do out of the actions available to them at that time" ("Procrastinate Revisited," 645-46). According to Jackson, diachronic actualism does not create an "action dilemma" for Procrastinate, since "for each time of acting, and each action available to him at that time, there is a single answer concerning what he [Procrastinate] ought to do at that time" (ibid., 645). The suggestion seems to be that prescribing [notaccepting] as well as [accepting and writing] does not create a dilemma, because only [notaccepting at $t$ ] is really available at $t$, while [accepting at $t$ and writing at $t^{\prime}$ ] is not. This strikes me as misleading: [writing at $t^{\prime}$ ] is in the relevant sense (discussed in Sec. II. $A$ ) available at $t$; also [accepting at $t$ and writing at $t^{\prime}$ ] is in any sense at least partially available at $t$. But the sug- 


\section{Ethics July 2015}

me as plainly false that the deliberative question is only concerned with what to do now. Quite the contrary, a great deal of our practical reasoning is concerned with planning the future and coordinating intentional action over time. ${ }^{29}$ The deliberative question thus arises not only with respect to "short-term" actions in the immediate future, but also with respect to "long-term" (or "mid-term") projects or temporally extended courses of action. In other words, it makes perfect sense for Procrastinate to ask himself in deliberation, with a view to making a decision, whether he ought to [accept the invitation and write the review]. The correct answer to this deliberative question must be compatible with the correct answer to the deliberative question of whether he ought to [accept the invitation]. And this means that actualism, understood as a view about the deliberative 'ought', cannot be correct. ${ }^{30}$

\section{An Alternative Explanation of the Actualist Intuition}

I have argued that the actualist treatment of the case of Professor Procrastinate is untenable, which leaves me with the task of justifying an alternative response. As I see it, our pretheoretical intuitions about this case are in tension. There is a sense in which it seems right to refuse the invitation to write the review, but yet another sense in which doing this seems wrong. Actualists can explain this tension; according to them, it seems right to refuse because Procrastinate ought to refuse, and it seems wrong to refuse because he ought to accept and write. ${ }^{31}$ Denying actualism leaves one with the challenge of explaining the sense in which it seems right, for someone like Procrastinate, to refuse the invitation.

My suggestion is this: Procrastinate ought to accept the invitation, and he ought to write the review, but he also ought to make sure that if he will not write the review, he rejects the invitation. The 'ought' in question does not govern the particular action of rejecting the invitation, but the more complex action of making sure, bringing about, or seeing to it that this conditional is true. It is this 'wide-scope' ought that Procrasti-

gestion also misses the more general point made in the main text that there is a practical question not only about the immediate future but also about temporally extended courses of action, and that a theory that gives incompatible answers to these questions clearly does create practical dilemmas. Jackson's insight concerning synchronic cases should have led him to give up actualism about diachronic cases as well.

29. See, e.g., Michael Bratman, Intention, Plans, and Practical Reason (Cambridge, MA: Harvard University Press, 1987).

30. As has been argued convincingly in the literature, actualism needs also to be rejected for the further reason that it has unacceptable implications on the first-order normative level. See, e.g., Ross, “Actualism, Possibilism, and Beyond," sec. 1.

31. Compare Jackson and Pargetter, "Oughts, Options, and Actualism," 241. 
nates satisfies if he rejects the invitation and thus explains the sense in which it is right to do so. ${ }^{32}$ This answer not only explains the tension between our intuitions in this case, but does so without violating any of the plausible principles mentioned above, the transmission principle included. It is therefore the preferable account.

Jackson and Pargetter argue that "appeal to conditional obligation is beside the main point." 33 Moreover, they claim that "considerations to do with conditional obligation support that Procrastinate ought to say no: Detachment for conditional obligation is valid. If I ought to do $\mathrm{X}$ given $\mathrm{Y}$, and $\mathrm{Y}$ is the case, then I ought to do X." ${ }^{34}$ I agree with these claims. But my suggestion is not that Procrastinate is under a conditional obligation to refuse given that he will not write. Rather, he is under an obligation to make a conditional true. Such an obligation does not entail an obligation to make the consequent true if the antecedent holds; it may instead be satisfied by making the antecedent false.

It might be objected that both accounts have effectively the same implications, since on the assumption that Procrastinate will not write the review, the only way for him to satisfy the wide-scope obligation is to reject the invitation. But recall that the actualist argument against the transmission principle works only if we assume (as Jackson and Pargetter do) that Procrastinate can write the review. It is therefore false to say that the only way for him to satisfy the wide-scope obligation is to reject the

32. Actualism entails the conditional claim "If Procrastinate will not write the review, then he ought to reject the invitation." Here the 'ought' takes narrow scope, because it governs merely the consequent of the conditional (or the action referred to in the consequent). The 'ought' that I propose instead takes wide scope, because it governs the whole conditional (or the action of making this conditional true). Saying that the agent ought to "make sure," "see to it," or "bring it about" that the conditional holds is one way to express wide-scope 'oughts' in a manner that is compatible with the view that 'oughts' relate to actions (or responses) rather than propositions. It thus avoids an objection to wide-scope accounts along the lines of Mark Schroeder, "The Scope of Instrumental Reason," Philosophical Perspectives (2004): 337-64, 342-44, and "Ought, Agents, and Actions," Philosophical Review (2011): 1-41, 35-36. The other way is to understand wide-scope 'oughts' directly as disjunctive (Procrastinate ought to [write-the-review-or-reject-the-invitation]) or as conjunctive prohibitions (Procrastinate ought not to [accept-the-invitation-and-not-write-thereview]). I use the "making sure" construction here for reasons of convenience only; everything I go on to say could equally well be expressed by disjunctive 'oughts' or conjunctive prohibitions. In particular, by saying that Procrastinate ought to make sure that [if he will not write, he does not accept], I do not mean to suggest that Procrastinate ought, at the time of deciding whether to accept, to do something at that time, which guarantees the truth of the conditional. First accepting the invitation and then later writing the review is sufficient for him to make sure that the conditional holds in the sense that I take to be relevant (as is, of course, rejecting the invitation).

33. Jackson and Pargetter, "Oughts, Options, and Actualism," 237-38.

34. Ibid., 238. 
invitation; even if he will not write the review, he can do it, and thus can satisfy the wide-scope obligation by making the antecedent false. Thus, no obligation to reject the invitation can be detached.

It is unclear whether Jackson and Pargetter address this kind of reply because they do not seem to distinguish between narrow-scope conditional obligations and wide-scope obligations to make a conditional true. But from what they say about conditional obligations, it seems they would make the following two objections: first, in asking what he ought to do in deliberation or advice, Procrastinate is most naturally understood as wanting to know whether he ought to refuse or accept, and the wide-scope 'ought' does not answer this question satisfactorily. ${ }^{35}$ Again, I agree. But the possibilist has a clear answer to this question: Procrastinate ought to accept. Given how likely he is not to write the review, it seems also of considerable importance to tell Procrastinate that in accepting-and-not-writing, he would additionally violate the wide-scope obligation at issue, which he could avoid doing by violating the obligation to accept, whose normative significance in turn entirely depends on an obligation that he is going to violate anyway. Given that Procrastinate ought to [accept and write] (as actualists and possibilists agree), this is the most helpful advice we can give. In comparison, it is rather the actualist advice that is unsatisfactory, since it clearly is a criterion for good advice that it does not give incompatible instructions.

Second, Jackson and Pargetter seem to object that the wide-scope obligation holds independently of whether Procrastinate is in fact likely not to write the review and thus cannot account for the significance of this fact for the normative situation. ${ }^{36}$ There are two responses available on behalf of the wide-scope account. First, we could say that the widescope obligation is itself conditional on the fact that Procrastinate is likely not to write the review. ${ }^{37}$ Accordingly, this fact would significantly alter the normative situation, for it would impose the wide-scope obligation on Procrastinate from the start. Second, even if the wide-scope

35. Jackson and Pargetter (ibid., 237-38) make this point about conditional obligations, but it seems to apply just as well to obligations to make a conditional true.

36. Compare ibid., 239.

37. This possibility of conditional wide-scope 'oughts' is often overlooked in debates about wide-scope accounts, also with respect to the principle of instrumental rationality. As Way, "Defending the Wide-Scope Approach," 223, points out, the wide-scope principle of instrumental rationality could be understood as being conditional on the means/endbelief - alternatively, it could also be understood as being conditional on a desire to be rational or even on the end-intention. Hence, the question of scope should be distinguished from the question of conditionality, and there is no reason to reject wide-scope accounts on the ground that they presuppose unconditional 'oughts' as Errol Lord, "Violating Requirements, Exiting from Requirements, and the Scope of Rationality," Philosophical Quarterly 61 (2011): 392-99, 398-99, and Schroeder, “The Scope of Instrumental Reason,” 34041 , maintain. 
obligation is understood in an unconditional way, the objection is unpersuasive. For even though the fact that Procrastinate is likely not to write the review would then not make a difference for his first-order obligations, it could still make a difference to the normative situation, for example, by providing second-order reasons to adopt additional measures that ensure his conformity to his obligations. Compare the obligation not to drink and drive. If you are likely to drink, this might give you additional reasons to ensure that you will not violate this obligation, but this does not mean that with respect to drinking-and-driving you stand under obligations different from those of people who are unlikely to drink. Similarly, if you are unlikely to write the review, this could provide you with second-order reasons for adopting additional measures to ensure conformity with the obligation not to accept-and-not-write; it is not necessary to assume that it also makes a difference to what obligations you are under with respect to accepting and writing itself.

To sum up the discussion of this section, actualism implies that the transmission principle is false. But it also implies that the principle of joint satisfiability is false, which constitutes a reductio of this view. Moreover, we have seen that the intuitions invoked by the case of Professor Procrastinate can be captured without subscribing to actualism-by employing a wide-scope 'ought' that does not conflict with either the transmission principle or the principle of joint satisfiability. With these intermediate results on the table, we can now turn to explicit objections to the transmission principle from the recent literature.

\section{THE OBJECTIONS}

In this section, I shall discuss three alleged counterexamples to the transmission principle that have been put forward by John Broome (III.A), Joseph Raz (III.B), and Niko Kolodny (III.C). Though the details vary significantly, I shall argue that all three objections can be seen as different versions of the actualist challenge, that they rely on assumptions that are just as problematic as Frank Jackson and Robert Pargetter's, and that they can be dealt with in a manner that preserves the transmission principle.

Any counterexample to the transmission principle must involve two claims: that an agent ought to perform an action (call this the source 'ought'), and that it is not the case that this agent ought to take the necessary means (call this the instrumental 'ought'). One way to reject such an objection is to maintain the instrumental 'ought'; the other way is to deny the source 'ought'. The objections considered below all employ the intuition that a particular instrumental 'ought' is implausible because the agent will not, or is unlikely to, conform to a presumed source 'ought'; they differ, however, in another important respect. In Broome's 
example (as in the example of Jackson and Pargetter), the fact that the agent is unlikely to conform to the source 'ought' is due to an anticipated failure that the agent is responsible for and can avoid. In such a case, the possibilist response is to maintain the instrumental 'ought'. I have defended this response above, and I will show that it is also the most plausible analysis of Broome's example. However, both Raz and Kolodny make use of examples in which the fact that an agent is unlikely to conform to a presumed source 'ought' is not due to a failure of the agent. In such cases, the mentioned response is not available, and the instrumental 'ought' cannot be defended. I shall argue that such examples call instead for the rejection of the source 'ought'.

\section{A. Broome's Objection}

Let me start with a case that Broome raises against the transmission principle: suppose that you ought to see your doctor, and that taking a day off is a necessary means for doing so. The transmission principle entails that you ought to take a day off. But suppose that if you were in fact taking a day off work, you would not visit your doctor but instead sit around feeling anxious. In this case, Broome maintains, it is implausible to assume that you ought to take a day off. ${ }^{38}$

This objection is actualist in spirit, even though Broome does not commit himself to a general view of this sort, and he is cautious enough to restrict his claim to the absence of a requirement to take the necessary means (or, as I shall put it, a permission not to take them) rather than a requirement not to take them. This may seem to make his position less vulnerable, but the following two points should be noted. First, it is hard to see how Broome could not agree that you ought to [take a day off and see a doctor]. The distribution principle would allow us to draw the conclusion that you ought to take off, which contradicts Broome's claim that you are permitted not to take a day off. Hence, Broome's argument violates the distribution principle as well. Second, it is hard to see why, if the reasons to take a day off can be counterbalanced (without it being the case that the reasons for seeing the doctor are counterbalanced) in such a way that it is not the case that you ought to take a day off, they could not in principle be outweighed to the effect that you ought not to take a day off. So if Broome's example shows that you could be permitted not to take the necessary means, an example of the same structure should suffice to show that you ought not to take the necessary means. But then Broome also needs to deny joint satisfiability.

38. Compare Broome, Rationality through Reasoning, 126. Broome presents the example in terms of prudential requirements rather than 'oughts', but as he notes later, he rejects the transmission principle for 'ought' for the same reason (129). 
I suggest that we treat this case in the same fashion as the example of Professor Procrastinate. Instead of holding:

Broome's claim: If you will not see your doctor, you are permitted not to take a day off,

we should maintain:

Wide-scope permission: You are permitted to make sure that, if you will not see your doctor, you do not take a day off,

where this latter claim might plausibly be regarded as a mere consequence of:

Wide-scope 'ought': You ought to make sure that, if you will not see your doctor, you do not take a day off.

Since wide-scope permissions and 'oughts' do not allow for factual detachment, we cannot conclude that you are permitted not to take a day off, which was the claim that threatened the transmission principle. So we can both maintain the transmission principle and capture the sense in which it is true that you ought not (or that it is not the case that you ought) to take a day off if you will not see a doctor. Since we thereby avoid counterintuitive results, this reading is clearly preferable. Broome's example does not give cause to reject the transmission principle.

\section{B. Raz's Objection}

A different kind of example that appears to threaten the transmission principle is given by Joseph Raz:

if I have reason to visit my grandmother who lives on Easter Island today, I also have reason to buy a flight ticket to go there today, but only if . . . it is possible to get there by air today. If there is an air strike, I have no reason to pursue the plan of flying there today, and therefore no reason to buy a flight ticket. Such actions will not facilitate my visiting her, even though I still have reason to visit her today, albeit one with which (let us assume) it is impossible for me to conform. ${ }^{39}$

Raz discusses this case in the context of a principle about reasons rather than 'oughts', and it is unclear whether he intends it to call into question the transmission principle at issue here. But since it could be un-

39. Raz, "The Myth of Instrumental Rationality," 7. 
derstood in this way, it is worth considering whether a case of this sort can provide a counterexample to the transmission principle. In order for this to be so, we need to make the following two assumptions. First, we have to assume that the protagonist of the story (call him Joseph) not only has some reason to, but ought to visit his grandmother. Second, we have to assume that buying a plane ticket can count as a necessary means to visiting the grandmother even though visiting her is impossible. It then follows that, contrary to what the transmission principle implies, it is not the case that Joseph ought to take the necessary means to the action that he ought to perform.

Note that Raz presents his example as a "special case" of the more general rule that "if it is certain that I will not do the source action, whether or not I can do it, there is no reason to take the facilitative action." ${ }^{40}$ His objection is thus also actualist in spirit. Yet the possibilist strategy that I employed above to deal with counterexamples is not available here. Since the fact that Joseph will not visit his grandmother is not due to a failure in Joseph's exercising his agency, it does indeed undermine the claim that Joseph ought to buy a ticket.

However, it also undermines the claim that Joseph ought to visit his grandmother. Joseph is certain not to visit his grandmother because this is impossible for him, and given that this is true, we cannot maintain that Joseph still ought to visit his grandmother. At least, we cannot do so as long as we maintain the widely shared view that 'ought' implies 'can':

'Ought' implies 'can': If A ought to $\varphi$, then A can $\varphi \cdot{ }^{41}$

Now, Raz does indeed hold that there can be reasons to do what is impossible, and he does not explicitly exempt conclusive or decisive reasons from this claim. ${ }^{42}$ But as it stands, this thesis is surely counterintu-

40. Ibid., 7 n. 9 .

41. For a recent defense of this view, see Bart Streumer, "Reasons and Impossibility," Philosophical Studies 136 (2007): 351-84. Streumer argues, convincingly to my mind, that even pro tanto reasons imply 'cans'.

42. Compare Raz, "The Myth of Instrumental Rationality," 6: "No occasion of possible realization is presupposed by true propositions of (non-instrumental) reasons we have." See also ibid., 4. In more recent work, Raz seems to exempt conclusive reasons and 'oughts' from this thesis; see Joseph Raz, From Normativity to Responsibility (Oxford: Oxford University Press, 2011), 25. However, in the same book, Raz continues to make claims that are incompatible with 'ought' implies 'can', such as this one: "I ought to send my child to the best school, to avoid damaging my neighbor's tree, . . . and none of them arises out of any fault of mine. Therefore, if I cannot achieve them, I should come as near as possible, which may involve sending my child to the next best school, paying to cure the damage to my neighbor's tree" (192). 
itive, and Raz offers no arguments in its favor. ${ }^{43}$ Note further that since Raz's assumptions violate the principle that 'ought' implies 'can', they (trivially) also violate joint satisfiability. Moreover, both of the deliberative arguments that I have presented in support of joint satisfiability equally support the principle that 'ought' implies 'can'. A sense of 'ought' that did not imply 'can' could not be the sense of 'ought' in which believing one ought to $\varphi$ rationally commits one to intending to $\varphi$, for it would follow that just by believing the truth we could be rationally committed to intending actions which we believe to be impossible. Nor could such an 'ought' be the one that figures in answers to the practical question of what to do, for this question would have to be asked again when an action turned out to be impossible.

In any case, one cannot reject an intuitively compelling principle by presupposing that another intuitively compelling principle is false. Raz's example therefore does not threaten the transmission principle in any serious sense.

\section{Kolodny's Objection}

Finally, I shall discuss a case that Niko Kolodny has recently put forward as a counterexample to the transmission principle:

Consider Lucky and Unlucky, who occupy parallel universes. Each has an antique sitting on his front porch, which the rain threatens to ruin. A necessary means to saving the antique is taking a taxi back home. There is reason to refrain from taking the taxi; it costs money, say $\$ 20$. But this cost is outweighed by the value of the antique, say $\$ 100$. The only difference in their situations is that in Lucky's universe, the rain will be slow in coming, and so he is very likely to get him home in time, if he takes the taxi: say that the probability is .9. In Unlucky's universe, by contrast, he is extremely unlikely to get him home in time, even if he takes it: say .1. ${ }^{44}$

Kolodny argues that since Unlucky's taking a taxi is so unlikely to save the antique, it is not the case that Unlucky ought to take the taxi. How-

43. Drawing on Raz's work, Heuer, "Reasons and Impossibility," 235-46, has recently put forward two arguments to the effect that "a person may well have a reason (and even most reason) to do what she cannot do, but she cannot have most reason to try to do it, or to take the means to realizing it" (236). These arguments would provide support for the kind of counterexample to the transmission principle envisaged here, but I think they are effectively refuted by Bart Streumer, "Reasons, Impossibility and Efficient Steps: Reply to Heuer," Philosophical Studies 151 (2010): 79-86. The arguments in favor of joint satisfiability presented above add further and independent support to his refutation.

44. Kolodny, "Instrumental Reasons," sec. 2. 


\section{Ethics July 2015}

ever, Kolodny also maintains that Unlucky ought to save the antique. Since taking the taxi is a necessary means to saving the antique, these verdicts contradict the transmission principle.

Note that this is yet another version of the actualist challenge: as before, it is argued that an instrumental 'ought' is not in place because the agent is unlikely to conform to a putative source 'ought'. Since Unlucky's being unlikely to save the antique (in contrast to Procrastinate's being unlikely to write the review) is not up to him, the strategy of maintaining the instrumental 'ought' in this case seems implausible. Instead, I believe that we should reject the source 'ought' and deny that Unlucky ought to save the antique.

Kolodny's argument that Unlucky ought to save the antique is that "Lucky ought to save the antique" and that "if Unlucky saves the antique, things will be exactly as they are if Lucky saves it." ${ }^{" 5}$ His overall argument against the transmission principle can thus be summarized as follows:

1. It is not the case that Unlucky ought to take the taxi.

2. Lucky ought to save the antique.

3. If Unlucky saves the antique, things will be exactly as they are if Lucky saves it.

4. Therefore, Unlucky ought to save the antique (from 2 and 3).

5. Therefore, the transmission principle is false (from 1 and 4).

The step from 2 and 3 to 4 is valid only on the assumption of some kind of bridge principle along the following lines:

Bridge principle: Whether A ought to $\varphi$ depends only on how things are likely to be, or will be, if $\mathrm{A} \varphi$-s. ${ }^{46}$

This principle presupposes actualism: according to it, whether we ought to act in a certain way depends only on what would happen (or would likely happen) if we acted in this way, irrespectively of what could happen as a result of exercising our agency. It can easily be shown that this principle (or any other principle that bridges the gap in the argument) shares all the problems of the actualist assumptions discussed above. ${ }^{47}$

45. Ibid., sec. 3 .

46. Kolodny explicitly embraced this principle (which he called "conditionalization principle") in an earlier draft of his article. But even though the forthcoming version no longer mentions it, the principle is still required for the argument that he presents. At least, it is unclear what else could license the inference from 2 and 3 to 4 . In any case, as will become clear below, the argument that I put forward against the bridge principle would equally apply to any other principle that licenses this inference.

47. The principle also has other controversial implications. For instance, since the bridge principle denies that considerations that are independent of an act's (expectable) consequences can influence what an agent ought to do, it entails a form of consequentialism. 
For one, the bridge principle suggests that Unlucky ought to save the antique, and that it is not the case that Unlucky ought to take the taxi (what would likely happen if he saved the antique is good, while what would likely happen if he took the taxi is not). But it likewise suggests that Unlucky ought to [take the taxi and save the antique], for what would happen if he did that is just as good as what would happen if he saved the antique. The bridge principle thus violates the distribution principle. For another, the example urges not only the conclusion that it is not the case that Unlucky ought to take the taxi, but also that Unlucky ought not to take the taxi, for the reason not to take it (definite loss of $\$ 20)$ is not on a par with, but outweighs, the reason to take it (.1 probability of saving $\$ 100) .{ }^{48}$ Since the bridge principle entails that Unlucky ought to save the antique, and it is not possible for Unlucky to save the antique and to not take the taxi, accepting the bridge principle forces us to give up not only the transmission principle, but the principle of joint satisfiability as well. Note that this point applies to any principle that validates Kolodny's argument and is thus independent of the exact formulation of the bridge principle.

Kolodny is aware of the fact that his position violates joint satisfiability. His response is the same as Jackson and Pargetter's: since the relevant 'oughts' are supposed to be understood as relative to different sets of options, they need not be jointly satisfiable..$^{49}$ But as I have argued above, a relativized concept of 'ought' that does not obey joint satisfiability cannot be the concept of 'ought' that figures in deliberative conclusions. A view about the deliberative 'ought' that violates this principle therefore cannot be correct.

If we reject the actualist assumptions on which Kolodny's argument rests, we can analyze the example in the following way. ${ }^{50}$ Since it is unlikely that Unlucky could save the antique if he took the taxi, the cab fare outweighs the chance of saving the antique, and he ought not to take the taxi. Ought he to save the antique? Well, he cannot save the antique at the time at which the rain announces itself (time $t$, for short), so the question must be understood as asking whether it is true, at $t$, that he ought to save the antique at the later time at which he would arrive at

48. This independently plausible claim also seems to follow from the bridge principle and Kolodny's "cost avoidance" principle: "If there is a positive probability, conditional on one's $X$-ing, that one's $X$-ing helps to bring it about that one avoids some cost $C$, then there is reason to $X$, whose strength depends on the cost and the probability" (Kolodny, "Instrumental Reasons," sec. 3).

49. Compare ibid., sec. 3, n. 31.

50. I am here assuming a version of possibilism that shares Kolodny's basic assumption that 'ought' is relative to probabilities. For a more detailed discussion of this kind of probability- and time-relative account of 'ought', see Kiesewetter, “'Ought' and the Perspective of the Agent." 


\section{Ethics July 2015}

home if he took the taxi (time $t^{\prime}$, for short). A view that respects the individual and joint satisfiability of 'oughts' must hold that at $t$, Unlucky ought to save the antique only if the following conditional holds: if Unlucky does everything he ought to do until $t^{\prime}$, then at $t^{\prime}$ he can save the antique. And since we are assuming that Unlucky ought not to take the taxi at $t$, it follows that if he does what he ought to do until $t^{\prime}$, he will not have taken the taxi, and consequently he will not be able to save the antique at $t^{\prime}$. For this reason, we should deny that Unlucky ought to save the antique, quite independently of the transmission principle.

I take this to be a tenable account of what is going on in the example. Since there are strong independent reasons against interpreting the example in Kolodny's way, this is all we need to conclude that the example does not actually support Kolodny's argument against the transmission principle and thus does not call this principle into question.

\section{AN ARGUMENT FOR THE TRANSMISSION PRINCIPLE}

In this essay, I have discussed an important challenge to the transmission principle, which finds expression in a number of recent objections to it. The challenge is to make good on the claim that we ought to take the necessary means to an action we ought to perform even if we will not actually perform this action or are very unlikely to do so. I have suggested different strategies for dealing with the counterexamples: if the fact that we are unlikely to, or will not, perform the action in question is due to the fact that we cannot perform it (or cannot perform it if we do what we otherwise ought to do), then we should reject the assumption that we ought to perform this action in the first place. If this fact is due to a failure in the exercise of our agency, then we should maintain that we ought to take the necessary means. The contrary intuition is better captured by saying that we ought to make sure that if we are not going to perform the action, we also do not take the means to it.

I motivated my responses independently, by drawing attention to the fact that the assumptions on which the objections considered above rely threaten not only the transmission principle but other plausible principles as well. Most notably, these assumptions all seem to violate:

Joint satisfiability: If A ought to $\varphi$ and A ought to $\psi$, then it is possible for A to $[\varphi$ and $\psi]$.

This calls for a diagnosis. Is there an internal connection between the joint satisfiability and the transmission principle? I shall conclude this essay by proposing such a connection. The transmission principle, I shall suggest, is entailed by the best explanation of joint satisfiability. 
Recall that I have been concerned with the 'ought' of what we have, all things considered, most reason to do. This raises the following question: How do reasons have to work in order for joint satisfiability to be true? What, in other words, explains that we can never have most reason to perform an action that is incompatible with another action we have most reason to perform? A natural explanation, I think, is that practical reasons obey the following principle:

Reason transmission: If $\mathrm{A}$ has a reason to $\varphi$, and $\psi$-ing is an incompatible alternative to $\varphi$-ing, then A has an equally strong reason not to $\psi .^{51}$

By way of illustration, suppose that Radiohead and Portishead both give concerts on the same evening, such that you cannot attend both their performances. Then, according to this principle, if you have a reason to go to the Radiohead concert, then you also have an equally strong reason not to go to the Portishead concert. This strikes me as plausible. When being asked why you did not go to the Portishead concert, it is very natural to cite the fact that Radiohead played on the same evening as your reason.

Reason transmission provides a plausible explanation for joint satisfiability. To see this, suppose that you have both reason to go to the Radiohead concert and reason to go to the Portishead concert. What we want to know is why it cannot be the case that you have most reason to go to the Radiohead concert and most reason to go to the Portishead concert under such circumstances. According to reason transmission, your reasons to go to the Radiohead concert provide equally strong reasons not to go to the Portishead concert. Thus, you can have most reason to go to the Portishead concert only if your reasons to go there are stronger than the reasons in favor of going to the Radiohead concert. But reason transmission tells us that the reasons to go to the Portishead concert also provide equally strong reasons not to go to the Radiohead concert. Since these reasons are, ex hypothesi, stronger than your reasons to go to the Radiohead concert, you cannot have most reason to go to the Radiohead concert. So given that you have most reason to go to the Portishead concert, you cannot have most reason to go to the Radiohead concert.

The crucial point, now, is that reason transmission not only explains joint satisfiability, but also entails the transmission principle. To illustrate, suppose again that you have most reason to go to the Radiohead concert and that buying a ticket is a necessary means for doing this. If

51. Note that this principle does not entail that the reason to $\varphi$ and the reason not to $\psi$ are one and the same fact. The reason against $\psi$-ing may instead be the fact that $\mathrm{A}$ has a reason to $\varphi$, or the fact that $\psi$-ing is an incompatible alternative to $\varphi$-ing, or some combination of these facts. 


\section{Ethics July 2015}

buying is a necessary means to going to the concert, then not-buying is an incompatible alternative to going to the concert. Thus, according to reason transmission, all your reasons to go to the concert provide reasons of equal strength against not-buying, and thus in favor of buying the ticket. Now in order for it to be false that you have most reason to buy the ticket, it would have to be the case that you have reasons against buying the ticket that are together at least not weaker than your reasons to buy it. ${ }^{52}$ But according to reason transmission, such reasons would also count, with equal strength, against going to the concert in the first place and thus falsify the assumption that you have most reason to do so. The transmission principle thus follows from reason transmission.

To sum up, my suggestion is that the transmission principle is entailed by the best explanation of the fact that practical 'oughts' must be jointly satisfiable. Like all abductive arguments, this argument is defeasible by providing an alternative plausible explanation. For the moment, I rest content with the conclusion that the considerations raised in this section provide us with a good independent reason to believe the transmission principle. The onus is on the opponent of the transmission principle to come up with a better explanation of the truth of joint satisfiability, which does not entail the transmission principle. Even if he were to do so, however, that would not change the fact that the transmission principle is intuitively plausible and that (as I hope to have shown) it cannot be refuted on grounds of the actualist assumptions that are commonly employed in arguments against it.

52. I say "at least not weaker than" rather than "at least equally strong" in order to allow for cases of incommensurability. 